$45-52$

\title{
Can clinical and radiological findings predict surgery for lumbar disc herniation? A systematic literature review
}

Authors Andrew P White ${ }^{1}$, James Harrop², Joseph R Dettori ${ }^{3}$

Institutions ${ }^{1}$ Harvard Medical School, Department of Orthopaedic Surgery, Beth Israel Deaconess Medical Center, Boston, MA, USA

${ }^{2}$ Departments of Neurological and Orthopedic Surgery, Jefferson Medical College Philadelphia, PA, USA

${ }^{3}$ Spectrum Research Inc, Tacoma, WA, USA

\section{ABSTRACT}

Study design: Systematic review.

Objective or clinical question: What clinical and radiological findings in patients with lumbar-herniated nucleus pulposus can serve as predictors of surgical intervention?

Methods: Articles published between January 1975 and August 2011 were systematically reviewed using Pubmed, Cochrane, National Guideline Clearinghouse Databases, and bibliographies of key articles. Each article was subject to quality rating and was analyzed by two independent reviewers.

Results: From 123 citations, 21 underwent full-text review. Four studies met inclusion criteria. Only baseline disability as measured by the Roland Disability Index (RDI) or the Oswestry Disability Index (ODI) was consistently associated with a greater likelihood of having discectomy surgery across multiple studies. With the current literature, we were not able to find an association between surgery and several characteristics including smoking status, body mass index, neurological deficit, positive straight leg testing, and level of herniation.

Conclusions: From the limited data available, it appears that individual radiographic and clinical features are not able to predict the likelihood of surgical intervention. Higher baseline disability measurements (Oswestry and Roland) did correlate, however, with surgical treatment. 


\section{STUDY RATIONALE AND CONTEXT}

Since most patients with symptomatic lumbar-herniated nucleus pulposus (HNP) will improve with nonsurgical treatment, and because it is difficult to predict which patients will not improve, nearly all are initially counseled to undergo nonsurgical care. Many experienced practitioners have observed, however, that certain types of patients with HNP are more likely than others to fail conservative management. To address this observation, and to help counsel patients with regard to the typical treatments used for their particular lumbar HNP, we investigated if there is radiographic or clinical factors that can predict surgical intervention in patients with lumbar HNP.

\section{CLINICAL QUESTION}

What clinical and radiological findings can serve as predictors for surgical intervention in patients with lumbar disc herniation?
Fig 1 Results of literature search.

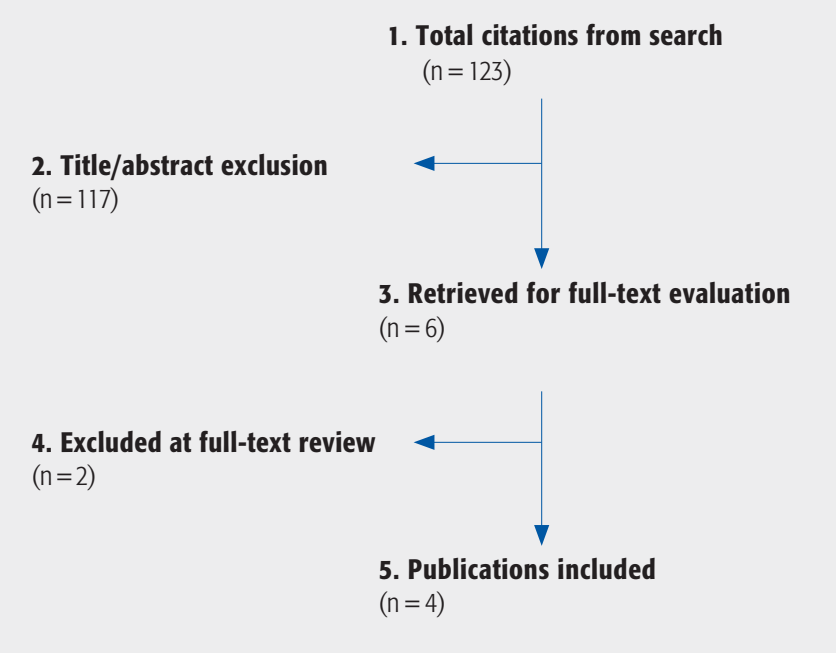

\section{METHODS}

Study design: Systematic review.

Objective: To determine if there is evidence to help predict if a patient with HNP will undergo surgical treatment. We sought studies that specifically evaluated prognostic factors that predicted whether a patient received surgery for HNP.

Inclusion criteria: (1) adults having had surgical discectomy for HNP; (2) an evaluation of elements from patient history (symptoms), physical examination (signs) or imaging; and (3) surgery as the outcome.

Exclusion criteria: (1) patients < 18 years old; (2) patients with trauma or cauda equina syndrome.

Sampling population: PubMed, Cochrane Collaboration Database, and bibliographies of key articles.

Dates searched: January 1975 through July 31, 2011.

Outcomes and prognostic factors: Lumbar discectomy surgery. For symptoms: pain (location, intensity or duration); neurological symptoms; aggravating factors; alleviating factors. For physical examination: neurological examination (motor or sensory); reflexes. For imaging: magnetic resonance imaging and computed tomography (MRI/CT).

Analysis: Descriptive.

Additional methodological and technical details are provided in the Web Appendix at www.aospine.org/ebsj 


\section{RESULTS}

From 123 citations, six underwent full-text review (Fig 1). Four studies met the inclusion criteria for assessing factors associated with the likelihood of decompression surgery [1-4] (Table 1). In the Web Appendix Table 2 provides the critical appraisal for these four studies, and Web Appendix Table 3 describes the reasons for excluding studies.

\section{Common prognostic factors evaluated in multiple studies (Table 2)}

More baseline disability was the only factor in more than one study that was associated with having surgery. Three studies consistently found that more baseline disability as determined by either the Roland Disability Index (RDI) or the Oswestry Disability Index (ODI) was associated with a higher possibility of discectomy surgery $[1,2,4]$. One study reported that there was a $70 \%$ increase in the odds of having surgery for every 3-point difference in the RDI (the adjusted odds ratio $=1.8[95 \%$ confidence interval, 1.2-2.9]) [2]. Descriptions of RDI and ODI are found in Table 3.

There were inconsistent results across three studies with respect to whether having an extruded or sequestered disc was associated with a higher probability of having surgery.

- Buttermann [1] reported on 50 patients who were enrolled in a conservative arm (epidural steroid injection) of a randomized control trial. Inclusion criteria were symptoms for at least 6 weeks and disc herniation occupying $>25 \%$ of the cross-sectional area of the spinal canal as measured on axial CT or MRI. Twenty-seven (54\%) underwent surgery. Those who had surgery were twice as likely to have an extruded or sequestered disc compared with those who did not undergo surgery (57\% vs $26 \%, P=.036)$.

- Peul et al [2] and Weinstein et al [4] found no association between herniation type (extruded, sequestered, or protruded) and the possibility of surgery. Weinstein et al, as part of the Spine Patient Outcomes Research

Table 1 Characteristics of included studies.*

\begin{tabular}{|c|c|c|c|}
\hline Author & Demographics $^{\dagger}$ & Inclusion criteria & Exclusion criteria \\
\hline $\begin{array}{l}\text { Buttermann [1] } \\
(2004)\end{array}$ & $\begin{array}{l}N=27 \\
\text { Male: NR } \\
\text { Age: mean, } 39 y\end{array}$ & $\begin{array}{l}\text { - Referred for treatment of lumbar disc herniation }>25 \% \\
\text { of the cross-sectional area of the spinal canal (as } \\
\text { determined by MRI or CT) }\end{array}$ & $\begin{array}{l}\text { - }<18 \text { y, }>70 \text { y } \\
\text { - Pregnancy } \\
\text { - Cauda equina syndrome } \\
\text { - Pars defect at the level of disc herniation } \\
\text { - Far-lateral disc herniation } \\
\text { - Multilevel symptomatic disc herniations } \\
\text { - Recurrent disc herniation }\end{array}$ \\
\hline $\begin{array}{l}\text { Peul et al [2] } \\
(2008)\end{array}$ & $\begin{array}{l}N=55 \\
\text { Male: NR } \\
\text { Age range, } 18-65 \text { y }\end{array}$ & $\begin{array}{l}\text { - 18-65 years of age } \\
\text { - Radiological confirmation of disc herniation } \\
\text { - Diagnosis from an attending neurologist of an } \\
\text { incapacitating lumbosacral radicular syndrome } \\
\text { - Symptoms for } 6-12 \text { wk }\end{array}$ & $\begin{array}{l}\text { - Cauda equina syndrome } \\
\text { - Muscle paralysis } \\
\text { - Insufficient strength to move against gravity } \\
\text { - Occurrence of similar episode during previous } 12 \text { mo } \\
\text { - Previous spine surgery } \\
\text { - Bony stenosis } \\
\text { - Spondylolisthesis } \\
\text { - Pregnancy } \\
\text { - Severe coexisting disease }\end{array}$ \\
\hline $\begin{array}{l}\text { Weinstein et al [4] } \\
\text { (2006) }\end{array}$ & $\begin{array}{l}\mathrm{N}=240 \\
\text { Male: } 61 \% \\
\text { Age: mean, } 43.0( \pm 11.3) \text { y }\end{array}$ & $\begin{array}{l}\text { - } \geq 18 \text { years of age } \\
\text { - Radicular pain } \\
\text { - Positive nerve root tension sign (straight leg raising or } \\
\text { femoral tension sign) or corresponding neurological } \\
\text { deficit (depressed reflex, decreased sensation, or } \\
\text { weakness) } \\
\text { - Radiological confirmation of disc herniation (MRI or CT) } \\
\text { - Diagnosis by participating physicians as having } \\
\text { intervertebral disc herniation } \\
\text { - Persistent symptoms despite nonoperative treatment for } \\
\text { at least } 6 \text { wk }\end{array}$ & $\begin{array}{l}\text { - Cauda equina syndrome } \\
\text { - Previous spine surgery } \\
\text { - Pregnancy } \\
\text { - Scoliosis }>15^{\circ} \\
\text { - Segmental instability }\left(>10^{\circ} \text { angular motion or }>4 \mathrm{~mm}\right. \\
\text { translation) } \\
\text { - Vertebral fracture } \\
\text { - Spine infection, tumor, or inflammatory } \\
\text { spondyloarthropathy } \\
\text { - Comorbid conditions }\end{array}$ \\
\hline Weber [3] (1983) & $\begin{array}{l}\mathrm{N}=66 \\
\text { Male }=55 \% \\
\text { Age: mean, } 41.7 \mathrm{y}\end{array}$ & $\begin{array}{l}\text { - Clinical symptoms and signs of a fifth lumbar and/or first } \\
\text { sacral root lesion } \\
\text { - Corresponding findings at radiculography }\end{array}$ & $\begin{array}{l}\text { - Spondylolisthesis } \\
\text { - Previous spine operations }\end{array}$ \\
\hline
\end{tabular}

* NR indicates not reported; MRI, magnetic resonance imaging; and CT, computed tomography.

${ }^{\dagger}$ Only includes patients in the conservative arm of a randomized control trial, of which some crossed over and received surgery. 
Trial (SPORT study), evaluated factors associated with having surgery in 240 patients who were randomized to receive conservative care. Of these, 107 (45\%) underwent surgery. Peul et al analyzed 142 patients from the conservative treatment arm of a randomized trial on lumbar disc surgery.

Several characteristics were not associated with having surgery in multiple studies. These include demographic characteristics (age, gender, occupation, smoking status, and body mass index), evidence of neurological deficit (depressed reflex, weakness in a myotomal distribution, or decreased sensation in a dermatomal distribution), positive straight leg testing, and level of herniation.

\section{Prognostic factors evaluated in single studies (Table 4)}

Single studies reported the following characteristics associated with receiving surgery: hydrated disc, lower income, a positive Kemp's sign, and higher-leg pain intensity, higher sciatica indices of frequency and bothersomeness, a lower SF-36v2 physical score, and symptoms that were getting worse at baseline.
Single studies found the following characteristics not associated with having surgery: comorbid conditions, pain with cough or sneeze, a positive-crossed straight leg raise test, education, employment status, inflammatory end plate changes on MRI, number of levels of degeneration, the patient's preference for surgery, or physical activity level.

\section{Clinical guidelines (published in the last 10 years)}

The American Pain Society: In patients with persistent and disabling radiculopathy due to herniated lumbar disc or persistent and disabling leg pain due to spinal stenosis, it is advised that clinicians discuss surgical risks and benefits as an option (strong recommendation, high-quality evidence). Also recommended is that shared decision-making regarding surgery include a specific discussion about moderate average benefits, which appear to decrease over time in patients who undergo surgery [5].

Within the limits of our inclusion and exclusion criteria, there were no clinical guidelines that specifically address clinical or radiographic characteristics that indicate surgery.

Table 2 Summary of predictive variables for discectomy surgery in patients with HNP reported in two or more studies.*

\begin{tabular}{|c|c|c|c|c|c|}
\hline & Summary & $\begin{array}{l}\text { Peul et al [2] } \\
(2008)\end{array}$ & $\begin{array}{l}\text { Buttermann [1] } \\
(2004)\end{array}$ & $\begin{array}{l}\text { Weinstein et al [4] } \\
(2006)\end{array}$ & $\begin{array}{l}\text { Weber et al [3] } \\
(1983)\end{array}$ \\
\hline Higher disability (Roland or Oswestry index) & + & + & + & + & $(-)^{\dagger}$ \\
\hline Extruded or sequestered disc & $+/-$ & - & + & - & \\
\hline Straight leg raising & $+/-$ & - & & + & - \\
\hline Age & - & - & - & - & - \\
\hline Gender & - & - & & - & - \\
\hline Occupation & - & - & - & - & - \\
\hline Spouse/partner & - & - & & - & \\
\hline Smoking status & - & - & - & - & \\
\hline Build/BMI & - & & & - & - \\
\hline Disability in earlier and latest attack & - & & & - & - \\
\hline Duration of symptoms & - & & - & & - \\
\hline Pareses & - & & & - & - \\
\hline Reflex & - & & & - & - \\
\hline Sensory disturbance & - & - & & - & \\
\hline Lumbar mobility & - & - & & & - \\
\hline Presence of pain & - & & - & - & - \\
\hline Onset timing of sciatica & - & - & & & - \\
\hline Level of herniation on MRI & - & - & - & - & - \\
\hline Workers' compensation claims or litigation & - & & - & - & \\
\hline
\end{tabular}

* HNP indicates herniated nucleus pulposus; BMI, body mass index; MRI magnetic resonance imaging; + indicates that the variable was found to be predictive of surgery; - indicates that the variable was not found to be predictive of surgery; a blank space indicates that the variable was not considered in the study.

${ }^{\dagger}$ Assessment of disability not described. 


\section{DISCUSSION}

Despite some relevant class I evidence, it can be difficult to guide patients who present with lumbar radicular pain caused by nerve root compression from a herniated disc. Weinstein et al [4] performed a prospective randomized study on surgery versus conservative treatment for lumbar disc herniation, as part of the SPORT study. Both surgery and conservative treatment demonstrated a high-satisfaction rate. The study was limited, however, in that the intention-to-treat analysis was hampered by a high-cross over rate. Only $50 \%$ of the surgery patients received surgery within 3 months and $42 \%$ of the conservative patients crossed over to surgical treatment. In the as-treated analyses there was a "strong, statistically significant advantages for surgery at all follow-up times through two years."

Some evidence suggests that delaying surgery may limit the effectiveness of surgical treatment [6]. As such, if prognostic factors were well established to help predict which patients would ultimately require surgery, treatment may be more effective. To use the SPORT trial as an example, if it were possible to predict which patients would be most likely to cross over to the surgical treatment arm, it would significantly aid in directing patients toward the most effective care. With this goal, this project was designed to examine the available prospective cohort literature on surgical versus conservative treatments for lumbar HNP. Specifically, patients who crossed over from the conservative arm to the surgical arm were evaluated to see what presenting factors were shared.

Each of the four selected studies had individual factors which the authors associated with increased odds of conservative patients requiring surgical intervention (Table $\mathbf{1}$ ). More consistent, however, were the factors that were not associated with surgical intervention (Table 2). All four articles reported no correlation between only two factors: patients' age and their occupation. Surprisingly, we were not able to demonstrate an association between surgical treatment and neurological symptoms, such as weakness, reflexes, or sensory disturbance. Weinstein et al [4] noted

Table 3 Description of patient-reported outcomes measures used [9].

\begin{tabular}{|c|c|c|c|}
\hline Measure & Components & Score range & Interpretation \\
\hline Oswestry Disability Index (ODI) & $\begin{array}{l}10 \text { subscales (10 items) } \\
\text { - Pain intensity } \\
\text { - Personal care } \\
\text { - Lifting } \\
\text { - Walking } \\
\text { - Sitting } \\
\text { - Standing } \\
\text { - Sleeping } \\
\text { - Sex life } \\
\text { - Social life } \\
\text { - Traveling } \\
\text { Each subscale score } 0-5 \text {, with total score doubled and written as a percentage }\end{array}$ & $0-100$ & $\begin{array}{l}\text { Higher score = greater } \\
\text { disability }\end{array}$ \\
\hline Roland-Morris Disability Index(RDI) & $\begin{array}{l}12 \text { categories (24 items) } \\
\text { - Pain intensity (2) } \\
\text { - Self-care (3) } \\
\text { - Social life (2) } \\
\text { - Walking (2) } \\
\text { - Sitting (2) } \\
\text { - Standing (1) } \\
\text { - Sleeping (2) } \\
\text { - Bending (1) } \\
\text { - Stairs (2) } \\
\text { - Appetite (1) } \\
\text { - General activity (4) } \\
\text { - Household chores (2) }\end{array}$ & $0-24$ & $\begin{array}{l}\text { Higher score = greater } \\
\text { disability }\end{array}$ \\
\hline
\end{tabular}


an association between positive straight leg raise and failure of conservative treatment but Peul et al [2] and Weber [3] reported no association to this physical examination sign.

The radiographic findings were less of a value than the clinical signs. The only positive correlation was the presence of a sequestered disc fragment, and this was noted only by Buttermann [1]. Weinstein et al and Peul et al noted no association of disc sequestration and need for surgical intervention (Table 2). Buttermann further analyzed the MRI images and noted that hydrated discs were more likely to need surgery (Table 4). Last, the level of disc herniation on MRI was reported in all four studies not to correlate with surgical intervention.
Based on the literature reviewed here, it currently appears that specific clinical and radiographic features do not seem to be helpful when directing and counseling patients with lumbar HNP. There appears, however, to be some factors that can help direct treatment options. The patient's baseline disability was the only factor in more than one study that was a prognostic factor for determining which patients would have lumbar decompressive surgery for acute disc herniations. Three of the four studies specifically noted a consistent finding of a greater baseline disability, as determined by either the RDI or ODI, was associated with an increased odds of having surgical intervention [1, 2, 4] (Table 4). In fact, Peul et al [2] noted a $70 \%$ increase in the odds ratio for every 3-point increase in the RDI score (the adjusted odds ratio $=1.8[95 \%$ confidence interval, 1.2-2.9]).

Table 4 Summary of predictive variables for discectomy surgery in patients with HNP reported in a single study.*

\begin{tabular}{|c|c|c|c|c|}
\hline & $\begin{array}{l}\text { Peul et al [2] } \\
(2008)\end{array}$ & $\begin{array}{l}\text { Buttermann [1] } \\
(2004)\end{array}$ & $\begin{array}{l}\text { Weinstein et al [4] } \\
(2006)\end{array}$ & $\begin{array}{l}\text { Weber et al [3] } \\
(1983)\end{array}$ \\
\hline Hydrated disc (more likely) & & + & & \\
\hline Lower income $(<\$ 50,000)$ & & & + & \\
\hline Positive Kemp's sign & + & & & \\
\hline Higher-leg pain intensity (VAS) & + & & & \\
\hline Patient self-assessed health trend & & & + & \\
\hline Higher sciatica indices (frequency and bothersomeness) & & & + & \\
\hline Sedentary work & & & & + \\
\hline Lower SF-36v2 score (more severe symptoms) & & & + & \\
\hline Symptoms worsening at baseline & & & + & \\
\hline Comorbid conditions & & & - & \\
\hline Cough, sneeze & - & & & \\
\hline Crossed-leg raising & - & & & \\
\hline Education & & & - & \\
\hline Employment status & & & - & \\
\hline Inflammatory end plate changes on MRI & & - & & \\
\hline Interval between back pain and radiating symptoms & & & & - \\
\hline Interval between first and latest attack & & & & - \\
\hline No. levels of degeneration & & - & & \\
\hline Patient preference for surgery & - & & & \\
\hline Physical activity & & & & - \\
\hline Psychosocial state & & & & - \\
\hline Race & & & - & \\
\hline Sciatica provoked by sitting & - & & & \\
\hline Size of herniation & & - & & \\
\hline
\end{tabular}




\section{SUMMARY AND CONCLUSION}

From the limited data available, it appears that individual radiographic and clinical features are currently not able to predict the likelihood of surgical intervention. Higher baseline disability measurements (ODI and RDI) correlated, however, with surgical treatment. We hypothesize that this is an area of promising future research. Future studies should aim to follow variables that may be used to predict surgical treatment, including straight leg raise test, and classification of herniation morphology such as far-lateral herniation.

\section{REFERENCES}

1. Buttermann GR (2004) Treatment of lumbar disc herniation: epidural steroid injection compared with discectomy. A prospective, randomized study. J Bone Joint Surg Am; 86$A(4): 670-679$.

2. Peul WC, Brand R, Thomeer RT, et al (2008) Improving prediction of "inevitable" surgery during non-surgical treatment of sciatica. Pain; 138(3):571-576.

3. Weber H (1983) Lumbar disc herniation: a controlled, prospective study with ten years of observation. Spine (Phila Pa 1976); 8(2):131-140.

4. Weinstein JN, Tosteson TD, Lurie JD, et al (2006) Surgical vs nonoperative treatment for lumbar disk herniation: the Spine Patient Outcomes Research Trial (SPORT): a randomized trial. JAMA; 296:2441-2450.

5. Chou R, Loeser JD, Owens DK, et al (2009) Interventional therapies, surgery, and interdisciplinary rehabilitation for low back pain: an evidence-based clinical practice guideline from the American Pain Society. Spine (Phila Pa 1976); 34:1066-1077.

6. Radcliff KE, Rihn J, Hilibrand A, et al (2011) Does the duration of symptoms in patients with spinal stenosis and degenerative spondylolisthesis affect outcomes? Analysis of the spine outcomes research trial. Spine (Phila Pa 1976); 36(25):2197-2110.

7. Osterman H, Seitsalo S, Karppinen J, et al (2006) Effectiveness of microdiscectomy for lumbar disc herniation: a randomized controlled trial with 2 years of follow-up. Spine (Phila Pa 1976); 31(21):2409-2414.

8. McMorland G, Suter E, Casha S, et al (2010) Manipulation or microdiskectomy for sciatica? A prospective randomized clinical study. $J \mathrm{Ma}$ nipulative Physiol Ther; 33(8):576-584.

9. Chapman JR, Hanson BP, Dettori JR, et al (2007) Spine Outcomes Measures and Instruments. 1st ed. Stuttgart New York: Thieme. 


\section{EDITORIAL PERSPECTIVE}

The reviewers unanimously applauded White et al for their important work and the diligence with which they handled this controversial topic. Increasingly, insurance carriers and government agencies focus on a number of clinical symptoms to warrant permission to obtain MRI scans for patients with suspected lumbar disc herniation, likely in an attempt to limit utilization frequency of these studies and thereby hoping to lower subsequent interventions resulting from perceived or real 'pathologic' MRI findings. Accordingly, a number of clinical algorithms based upon duration, distribution or severity of pain and neurologic symptoms have been suggested as 'decisionmaking' tools. In other words, if patients don't fit into these 'radicular symptom' categories they are likely to be denied MRI scans. This formal systematic review clearly shows that clinical symptoms bear no correlation to the eventual need for surgery and therefore clinical symptoms should not be reasonably used as decision-making tool to bar MRI scans.

This study again underscores the complexity of trying to understand lumbar disc herniations and their subsequent pathway. After reading this paper it can now be safely assumed that individual patient and surgeon preferences continue to ultimately influence the choice of surgical versus nonoperatively management. Such preferences were not evaluated in this study. However, it was assumed that surgery was only offered after failure of adequate conservative treatment.

From a practitioner standpoint there has been a long-held notion that have suspected certain patients with HNP to be more likely than others to fail conservative care. The authors identified this to be a clinical anecdote, without support in the literature. While many practitioners may think that focal weakness, a positive straight leg raise, or a certain subtype of disc herniation, such as a foraminal disc herniation, may be associated with failure of conservative care, there is very little concrete information on this in the literature.

The most remarkable finding of the authors was to show the importance of abnormal baseline disability scores, specifically the $O D I$ and the RDI scores, as being predictive of eventual surgical treatment needs. This, finally, is indeed a welcome and concrete ray of hope for future research in this pleomorphic and rather perplexing topic of what to do with lumbar disc herniations. 